\title{
Transfer of Ultrafine Particles and Air in Multi-storey
}

\section{Buildings}

\author{
Amalie Gunner, Siamak Rahimi Ardkapan, Alireza Afshari and Niels Christian Bergsøe \\ Department of Energy and Environment, Danish Building Research Institute, Aalborg University, Copenhagen S 2200, Denmark
}

\begin{abstract}
An emerging issue in Denmark is passive smoking in residential buildings where non-smokers are exposed to smoke from their neighbours. There are various ways that smoke is transferred from one flat to another. The air transfer rate between two flats in a multi-storey building depends on its construction, tightness and age. This paper presents results of a study on the transfer of ultrafine particles and tracer gas in an older multi-storey building in Copenhagen. The aim of the study was to quantify the transfer of ultrafine particles and gases from one flat to another flat before and after sealing the floor. A new floor-sealing method was applied to seal the floor between the two flats. The sealing method was developed by a firm specialising in sealing. Indoor ultrafine particle concentrations and tracer gas were measured continuously in the two flats during the measuring periods. In the unoccupied flat, the gas source was $\mathrm{N}_{2} \mathrm{O}$ and the particle source was burning cigarettes. Reduction of the concentration of ultrafine particles and tracer gas by sealing the floor with polyethylene and joint filler made of bitumen was studied. It was evaluated how the sealing performed with regard to decreasing the amount of ultrafine particles and a tracer gas transferred between two flats separated by a floor. When the floor between the flats was not sealed, the results showed that about $4 \%$ of the ultrafine particles and $14 \%$ of the tracer gas were transferred. After sealing, the amount transferred was reduced to $1.6 \%$ and $5 \%$, respectively.
\end{abstract}

Key words: Particles, air pollution, ventilation, full-scale experiments.

\section{Introduction}

In multi-storey buildings, it may occur that residents are exposed to the polluted air from the surrounding flats. The polluted air is usually associated with odour from activities such as cooking and/or tobacco smoking. Tobacco smoke is harmful and therefore technical solutions need to be developed in order to reduce the transfer rate of UFP (ultrafine particles) in multi-storey buildings.

To what extent air pollution - airborne particles-is transferred from one flat to another depends on the construction of the building, its age, density and ventilation system. An earlier study examined the transfer of UFPs from one flat (source flat) to another (exposed flat) [1]. The study showed that approximately $9 \%$ of the particles from tobacco smoke are transferred when the exposed flat is directly above

Corresponding author: Amalie Gunner, Ph.D. fellow, research fields: energy and environment. E-mail: amg@sbi.aau.dk. the source flat.

Previous research is studied three technical solutions to reduce the transfer of UFPs in multi-storey buildings [2]. The first study examined the sealing of the floor of the exposed flat. The other study examined the use of a novel air cleaning duct (photochemical air purification) and the third examined a portable AC (air cleaner).

The first technical solution was tested in a flat in a multi-storey building from the 1930s. Cardboard and plastic foil of polyethylene was used for sealing the whole existing wooden floor in the exposed flat. The results of the study showed that after the sealing, the concentration in the exposed flat was independent of the generation of UFPs in the source flat.

The second solution was examined in a laboratory environment. The efficiency of the novel air circulating ductwork was examined by investigating the removal rate of UFPs from a lit cigarette. The test showed that the efficiency of the removal rate went from $30 \%$ to $60 \%$ after $10 \mathrm{~min}$, i.e., when the cigarette had burned out. 
The third solution with a portable air purifier was investigated in a flat of $110 \mathrm{~m}^{2}$. In this case, the efficiency of an air cleaner was studied in relation to the reduction UFPs from tobacco smoke. By using an air purifier with a CADR (clean air delivery rate) of $240 \mathrm{~m}^{3} / \mathrm{h}$ the effectiveness of the air purifier ranged between $65 \%$ and $75 \%$ depending on its location in the flat in relation to the location of the UFP generating source [3].

Older multi-storey buildings often have leaks that UFPs can pass through. There are leaks from piping in the floor and along the walls. Studies show that UFPs are not only transferred through the floor but also along the stairwell [1].

This study investigates a new sealing method. It shows that application of the sealing method reduces the transfer of air and particles between two flats.

\section{Methods}

The study was carried out in a block of flats built in 1881. The exposed flat was directly which is above the source flat. The experiments were performed in January and February 2012. During measurements, no indoor activities took place-i.e., cooking, cleaning or other activities that could generate particles.

Fig. 1 shows the floor plans of the two flats. The exposed flat and the source flat are laid out the same way. The volume of the flat is approximately $120 \mathrm{~m}^{3}$. The flats consisted of a living room facing a busy road, a room and a kitchen facing a courtyard, a combined toilet/bath and an entrance centrally located in the flat. The floor of the flats was a varnished wooden floor in the living room, the room and the entrance. The kitchen had vinyl flooring and the bathroom floor was covered with tiles. The kitchen had cabinets along the inner walls and a sink under the window. The living room and the room had skirting boards along the walls and the ceiling had mouldings. A rosette with a power outlet was positioned in the middle of the ceiling of the living room and the room. A radiator with a heat pipe leading through the floor was placed under each

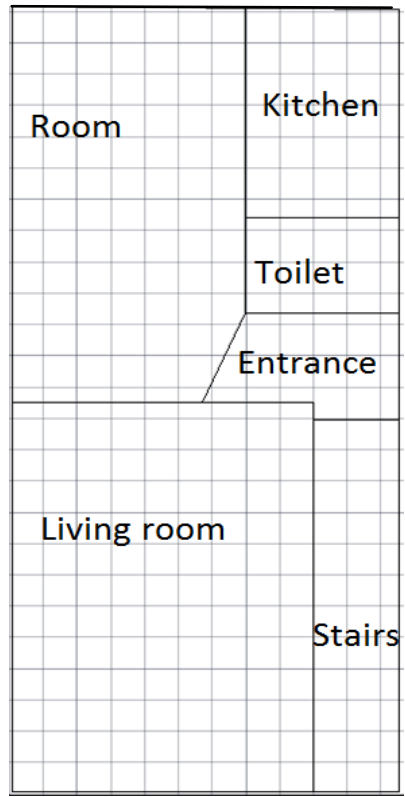

Fig. 1 Floor plan of the flats.

window in the living room and the room. There was ventilation in the toilet/bathroom. All the windows had fresh air vents.

With the purpose of creating an overpressure in the source flat compared with the exposed flat, a higher temperature was established in the source flat. This was ensured by maintaining the temperature of the source flat at $5{ }^{\circ} \mathrm{C}$ above the temperature in the exposed flat. During the examination, the temperature in the exposed flat was approximately $20{ }^{\circ} \mathrm{C}$ and in the source flat it was approximately $25^{\circ} \mathrm{C}$.

The UFP generating source consisted of four lit cigarettes that were placed in the lower flat, two in the living room and two in the room. All cigarettes were simultaneously extinguished after a period of $10 \mathrm{~min}$. The UFP concentration was measured by means of two particle counters NanoTracer PNT 1000 from Philips and one CPC (condensation particle counter) model 3007 from TSI Incorporated. The particle counters measured concurrently. The two NanoTracer PNT 1000 were placed in each of the flats and the CPC 3007 was placed outside.

Besides particles, the air change rate and the air transfer rate between the flats were measured by means of two Multi-Gas monitors, type 1302 from Brüel and 
Kjær, placed in each of the flats. Temperature and humidity were measured every 5 min with TinyTag data loggers type TGU-4500 from Gemini. During UFP generation complete mixing was achieved by means of small fans in the room. A top window in the façade the busy road was opened approximately $2 \mathrm{~cm}$ in the source flat. All fresh air vents were also opened and the exhaust in the toilet/bath was closed. In the exposed flat, all windows, exterior doors and fresh air vents were closed. In the toilet, the exhaust was open.

The first part of the experiment was performed without sealing the floor in the exposed flat. The second part of the experiment was carried out after the floor had been sealed in the exposed flat.

When the measurements were started, the UFP concentration in the flat was almost constant with a background concentration of about 10,000 UFP per $\mathrm{cm}^{3}$ in the source flat. In the exposed flat, the background concentration was 4,000 particles per $\mathrm{cm}^{3}$. Four cigarettes were lit in the source flat, two in the room and two in the living room. The cigarettes were extinguished just before they burned out. The measurements continued until the UFP concentration in the two flats almost reached the initial concentration.

Before the last measurements, the floor in the exposed flat was sealed. The sealing method was developed by a firm specialising in sealing. The company chose to seal the floor by fitting a vapour barrier, Icopal Blackline, made of polyethylene. The vapour barrier was made by overlapping pieces bonded together with joint filler made of bitumen. The vapour barrier was placed along the floor and up the walls, where it was sealed along the skirting boards with a building sealant approved for indoor use. At the heating pipes, the vapour barrier was sealed with joint filler made of bitumen. It was not part of in this study to determine whether the products used contributed to the concentration of particles in the exposed flat.

\section{Calculation Methods}

The transfer of UFPs and gas was calculated by applying a calculation method Eq. (1) used in previous experiments on second-hand smoke [1].

$$
\begin{aligned}
c_{r(t)} & =\frac{c_{s} \dot{V}}{\dot{V}+r V}+\frac{\dot{M}}{\dot{V}+r V} \\
& -\frac{\dot{V}}{\dot{V}+r V}\left[c_{s}+\frac{\dot{M}}{\dot{V}}-\frac{\dot{V}+r V}{\dot{V}} c_{r(0)}\right] e^{-\left[\frac{\dot{V}}{V}+r\right] \tau}
\end{aligned}
$$

where,

$\dot{V}$ is the airflow rate $\left(\mathrm{m}^{3} / \mathrm{h}\right)$;

$\dot{M}$ is the UFP transfer from flat 1 to flat 2 $\left(\left(\right.\right.$ particles $\left.\left./ \mathrm{m}^{3}\right) \cdot\left(\mathrm{m}^{3} / \mathrm{h}\right)\right)$;

$c_{s}$ is the UFP concentration in supply air (particles $/ \mathrm{m}^{3}$ );

$c_{r}$ is the UFP concentration of air in the flat (particles $/ \mathrm{m}^{3}$ );

$V$ is the volume of the flat $\left(\mathrm{m}^{3}\right)$;

$R$ is the UFP removal rate $\left(\mathrm{h}^{-1}\right)$.

The air change rate in the two flats was calculated by applying the decay method and the air change rate was determined by dosing a tracer gas in the flat 2 .

The tracer gas was distributed in a way that total mixing was guaranteed. After dosing of the tracer gas, the decay rate of the tracer gas was measured over time. The air change rate was calculated by the decay curve.

$$
C(t)=C_{0} e^{-n t}
$$

where,

$C_{0}$ is the initial concentration in ppm;

$C(t)$ is the concentration in ppm after $t$;

$t$ is the time in hours;

$n$ is the air change rate in $h^{-1}$.

\section{Results}

\subsection{Before Sealing}

Four cigarettes were lit in the source flat, two in the living room and two in the room. The cigarettes were lit at the same time and extinguished just before they burned out. Fig. 2 shows them easured UFP concentrations in the source flat and the exposed flat. Before UFP generation, the background concentration of UFPs in the source flat was approximately 10,000 $\mathrm{UFP} / \mathrm{cm}^{3}$ and in the exposed flat approximately 4,000 $\mathrm{UFP} / \mathrm{cm}^{3}$. The reason for the high background 
concentration in the source flat was that the resident in the source flat was a smoker and smoked indoors. The UFPs from the tobacco smoke deposited on surfaces such as furniture, walls and curtains [4]. The maximum UFP concentration in the source flat was measured at approximately $650,000 \mathrm{UFP} / \mathrm{cm}^{3}$. In the exposed flat, the maximum UFP concentration was measured at approximately $11,000 \mathrm{UFP} / \mathrm{cm}^{3}$. Fig. 2 shows that the maximum concentration in the exposed flat took place $30 \mathrm{~min}$. after the cigarettes were extinguished.

The transfer rate of UFPs from the source flat to the exposed flat was found to be approximately $4 \%$.

The air change rate in the source flat was calculated at $1.25 \mathrm{~h}^{-1}$ and at $0.18 \mathrm{~h}^{-1}$ in the exposed flat.

The transfer rate of tracer gas was calculated at approximately $14 \%$, as is shown in Fig. 3.

\subsection{After Sealing}

After sealing, the transfer rate of UFPs was reduced from $4 \%$ to $1.6 \%$ and the transfer rate of tracer gas was reduced from $14 \%$ to $5 \%$. The results showed that sealing more than halves the transfer of UFPs and tracer gas.

After the cigarettes were lit in the source flat, the concentration in the exposed flat was at the highest level after approximately $30 \mathrm{~min}$, as is shown in Fig. 4.

The initial UFP concentration in the exposed flat was higher at the beginning of the experiment, than when the cigarettes in the source flat were ignited. This was because the residents were at home right up to the start of the study.

After sealing the floor in the exposed flat, the air change rate in the source flat was calculatedat $1.46 \mathrm{~h}^{-1}$. In the exposed flat, the air change rate was calculated at $0.52 \mathrm{~h}^{-1}$. The air change rate before sealing the floor was $1.25 \mathrm{~h}^{-1}$ and $0.18 \mathrm{~h}^{-1}$, respectively. The difference in the air change rate may be due to the fact that when the floor was sealed, a hole was made in the outer wall for a balcony. During the experiment the hole was sealed with a mattress but no insulation. As the flat was less insulated the transfer might have influenced the air change rate resulting in a different air change rate. The wind speed for outdoor air was on average $6 \mathrm{~m} / \mathrm{s}$ and 3 $\mathrm{m} / \mathrm{s}$ in both cases [5]. This indicated that the wind speed cannot explain the increase in the air change rate.

After sealing the floor of the exposed flat, the transfer rate of tracer gas from the source flat was calculated at 5\%, as is shown in Fig. 5. Before sealing the floor the transfer rate was $14 \%$.

\section{Discussions}

There are more than 30 different VOCs (volatile compounds) in tobacco smoke and highly volatile compounds deposit on surfaces and in the indoor environment where the pollution occurs [6]. Tobacco smoking generates more than 4,000 different chemical compounds during combustion [1]. During combustion, both gases and particles are emitted. For most people, odour limits whether or not tobacco smoke is acceptable in the indoor environment. The concentration of the particles depends on their volatility [7]. The concentration of particles also depends on temperature (increasing degassing with increasing temperature), humidity changes and ventilation [4]. Some of the particles deposit on other materials, in particular furry textiles. If for example, the air change rate is low during a weekend the emitting products deposit in the indoor environment. They do not disappear just because the space is ventilated.

\subsection{Gas}

To investigate the transfer of gases, a tracer gas of $\mathrm{N}_{2} \mathrm{O}$ was used. Since a lit cigarette emits thousands of different gases consisting of several molecules, it is not possible to measure the mall. Instead a measurable nitrogen tracer gas was used.

The investigation showed that the transfer of tracer gas was reduced from $14 \%$ to $5 \%$ after sealing the floor in the exposed flat. 


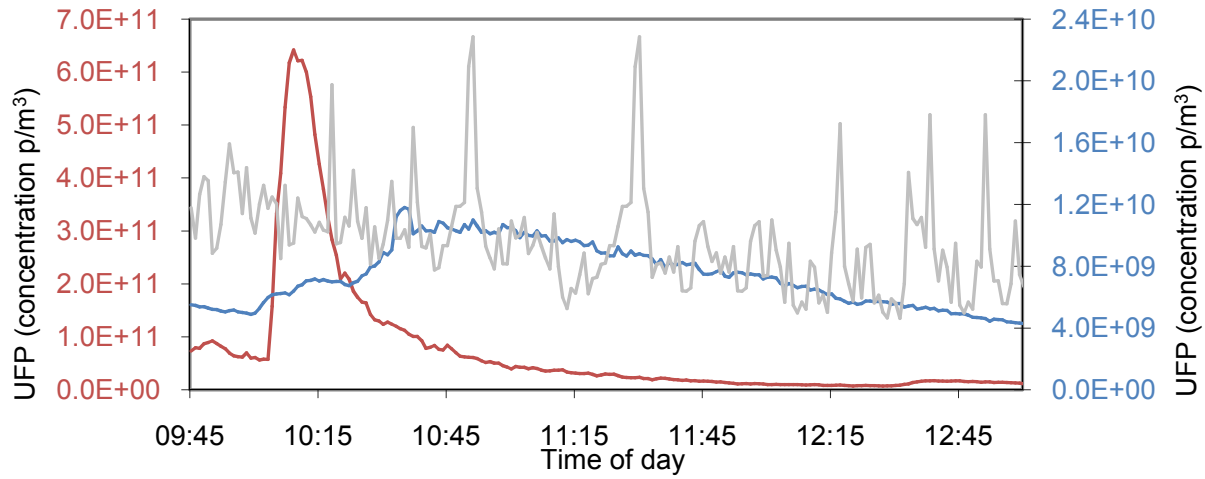

Fig. 2 UFP concentration in the flats (red: the source flat, blue: the exposed flat, grey: outdoor).

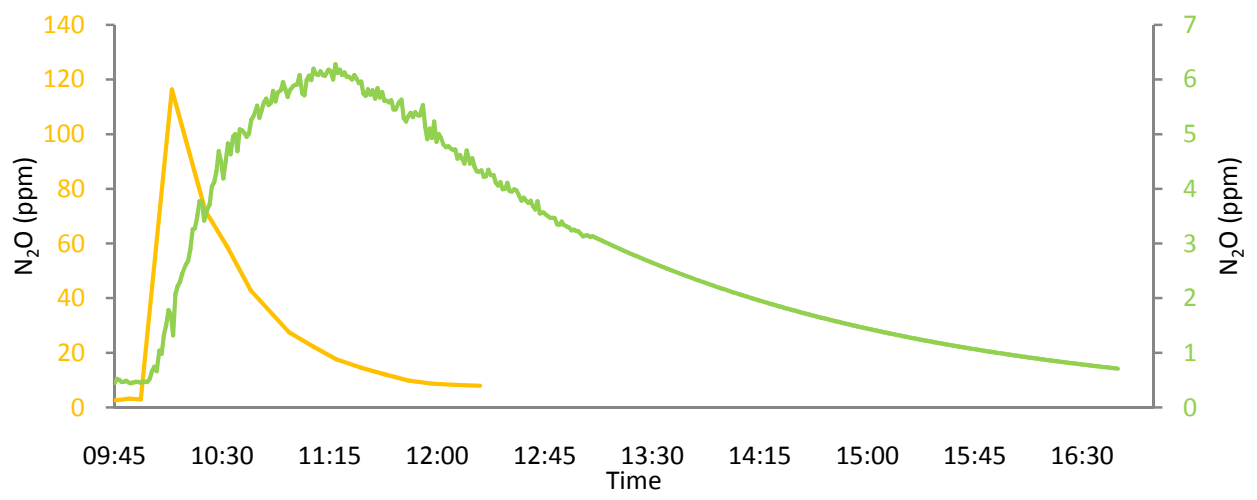

Fig. 3 Tracer-gas concentration in the two flats (yellow: the exposed flat, green: the source flat).

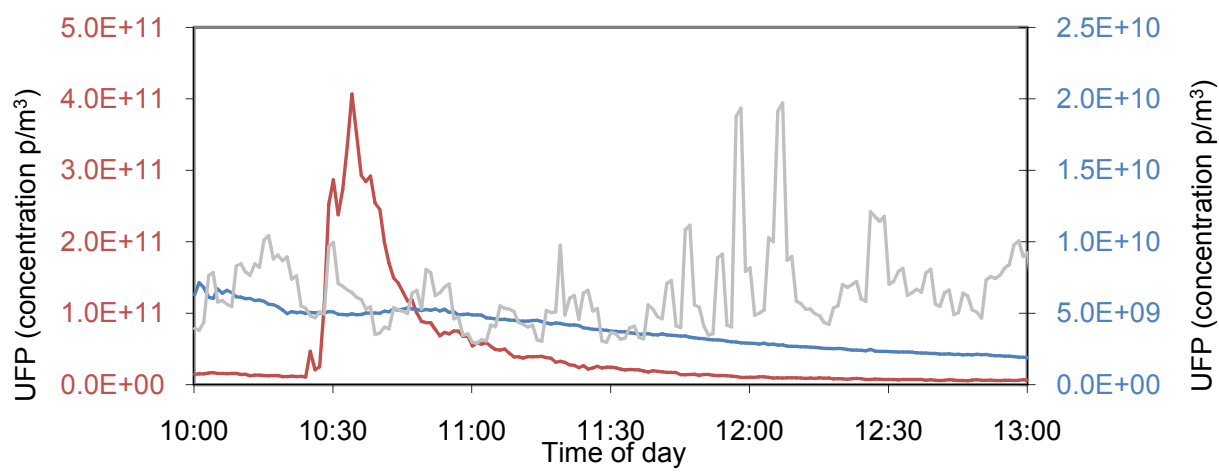

Fig. 4 UFP concentration in the flats (red: the source flat, blue: the exposed flat, grey: outdoors).

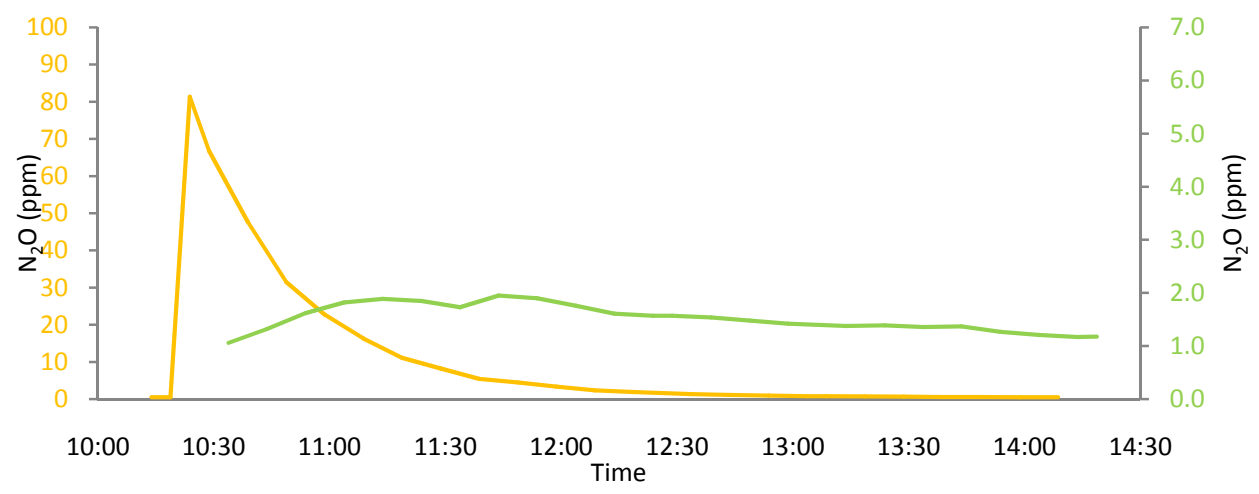

Fig. 5 Tracer-gas concentration in the two flats (yellow: source flat, green: exposed flat). 
Because the dosed tracer gas was $\mathrm{N}_{2} \mathrm{O}$, the measurements were certain to be only of the tracer gas. However, it was uncertain whether it was transferred through the floor or through other leaks in the structure.

Since only a single gas of a specific chemical compound was measured, it is difficult to say how much the gasses from tobacco smoke can be reduced, when compared with the large amount of different gasses in tobacco smoke.

\subsection{Ultrafine Particles}

The transfer of UFPs was examined by measuring the concentration before and after the floor was sealed. The transfer rate of UFPs was reduced from $4 \%$ to $1.6 \%$ after sealing the floor of the exposed flat.

This study showed that the transfer rate of UFPs was lower than the transfer rate of tracer gas. During the experiments without a sealed floor, $14 \%$ of the tracer gas was transferred while only $4 \%$ of the UFPs were transferred. This could be due to the fact that the UFPs deposition surfaces such as furniture and walls, and in cracks in the flat. Other factors, such as coagulation, sedimentation, condensation of water vapour on small particles, etc., also play a role.

\section{Conclusions and Future Work}

The applied sealing method resulted in a reduction of UFPs and tracer gas from the source flat to the exposed flat by more than half.

After the floor was sealed in the exposed flat, the transfer of UFPs was reduced from $4 \%$ to $1.6 \%$. This was less than half of what was transferred before the floor was sealed. Transfer of gases was reduced from a transfer rate of $14 \%$ to $5 \%$.

The investigation was performed in an older multi-storey building from the late 1800s. In Copenhagen, there are great many buildings of this kind. To verify the study, it is necessary to test several different types of multi-storey buildings.

New sealing materials are being developed and there is a need to test them in various types of buildings.

\section{References}

[1] A. Afshari, B. Shi, N.C. Bergsøe, L. Ekberg, T. Larsson, Quantification of ultrafine particles from second-hand tobacco smoke, in: 10th REHVA World Congress Sustainable Energy use in Buildings, Turkey, 2010.

[2] A. Afshari, S.R. Ardkapan, N.C. Bergsøe, M.S. Johnson, Technical solutions for reducing indoor residential exposures to ultrafine particles from second-hand cigarette smoke infiltration, in: 12th International Conference on Indoor Air Quality and Climate, Turkey, 2011.

[3] B. Shi, L.A. Ekberg, A. Afshari, N.C. Bergsøe, The effectiveness of portable air cleaners against tobacco smoke in multizone residential environments, in: 10th REHVA World Congress Sustainable Energy Use in Buildings, Turkey, 2010.

[4] O. Preining, The physical nature of very, very small particles and its impact on their behavior, J. Aerosol Sci. 29 (5-6) (1998) 481-495.

[5] DMI Web Site, http://www.dmi.dk/dmi/index/ (accessed Mar. 9, 2012)

[6] A. Afshari, C. Reinhold, Deposition of fine and ultrafine particles on indoor surface materials, Indoor and Built Environment 17 (3) (2008) 247-251.

[7] Are You Exposed to Smoke from Your Neighbors?, The Danish Cancer Society, http://www.cancer.dk/rensluften/ Naborog/er+du+udsat+for+naborog/er+du+udsat+for+na borog.htm?NRMODE $=$ Published $\&$ NRNODEGUID $=\{$ A DA1F4BA-AC27-4D39-A257-82283C166D65 $\} \& N R O R$ IGINALURL $=/$ rensluften/Naborog/er+du+udsat+for + nab orog/\&NRCACHEHINT $=$ Guest (accessed Aug. 23, 2012). 